\title{
Pulmonary resections performed at hospitals with thoracic surgery residency programs have superior outcomes
}

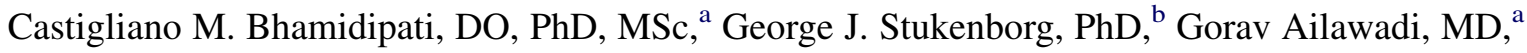 \\ Christine L. Lau, MD, ${ }^{\mathrm{a}}$ Benjamin D. Kozower, MD, MPH, ${ }^{\mathrm{a}}$ and David R. Jones, MD ${ }^{\mathrm{a}}$
}

\begin{abstract}
Objective: Pulmonary resections are performed at thoracic residency (TR), general surgery residency (GSR), no surgery residency, and no residency hospitals. We hypothesize that morbidity and mortality for these procedures are different between hospitals and that operations performed at TR teaching hospitals have superior results.
\end{abstract}

\begin{abstract}
Methods: Records of adults who underwent pneumonectomy, lobar, segmentectomy, and nonanatomic wedge resections $(\mathrm{N}=498,099)$ were evaluated in an all-payer inpatient database between 2003 and 2009. Hospital teaching status was determined by linkage to Association of American Medical College's Graduate Medical Education Tracking System. Multiple hierarchical regression models examined the in-hospital mortality, occurrence of any complication, and failure to rescue.
\end{abstract}

Results: The mean annual pulmonary resection volume among hospitals was TR $(16 \%)$, GSR (17\%), no surgery residency $(28 \%)$, and no residency $(39 \%)$. Unadjusted mortality for all procedures was lowest at TR hospitals $(P<.001)$. Likewise, any complication was least likely to occur at TR hospitals $(P<.001)$. After case-mix adjustment, the risk of any complication after segmentectomy or nonanatomic wedge resection was lower at TR hospitals than in GSR hospitals $(P<.001)$. Among pneumonectomy recipients, TR hospitals reduced the adjusted odds ratio of failure to rescue by more than $25 \%$ compared with no surgery residency $(P<.001)$. Likewise, in patients who underwent pneumonectomy, TR centers were associated with reducing the odds ratio of death by more than $30 \%$ compared with GSR hospitals $(P<.001)$.

Conclusions: In comparison with other hospitals, including GSR hospitals, TR hospitals have lower morbidity and mortality. These results support using hospitals with a TR as an independent prognostic indicator of outcomes in pulmonary resections. (J Thorac Cardiovasc Surg 2013;145:60-7)

Supplemental material is available online.

The regulatory climate in the United States has led to increased scrutiny of postsurgical quality and outcomes, including those after pulmonary resections, and as such, center and surgeon performance data are being made readily accessible. ${ }^{1-3}$ As a quality indicator, the Center for Medicare and Medicaid Services intends to expand public reporting of procedure-related outcomes. ${ }^{3-6}$ It is anticipated that similar to coronary artery bypass grafting,

From the Division of Thoracic and Cardiovascular Surgery, ${ }^{a}$ Department of Surgery, and Division of Patient Outcomes, ${ }^{\text {b }}$ Policy \& Population Research, Department of Public Health Sciences, University of Virginia School of Medicine, Charlottesville, Va.

Disclosures: Authors have nothing to disclose with regard to commercial support.

Read at the 92nd Annual Meeting of The American Association for Thoracic Surgery, San Francisco, California, April 28-May 2, 2012.

Received for publication April 30, 2012; revisions received Sept 21, 2012; accepted for publication Oct 2, 2012; available ahead of print Nov 9, 2012.

Address for reprints: David R. Jones, MD, Department of Surgery, University of Virginia School of Medicine, PO Box 800679, Charlottesville, VA 22908-0679 (E-mail: djones@virginia.edu).

$0022-5223 / \$ 36.00$

Copyright (c) 2013 by The American Association for Thoracic Surgery http://dx.doi.org/10.1016/j.jtcvs.2012.10.015 other procedures, such as pulmonary resections, will be included in such reports. Pulmonary resections, such as pneumonectomy, lobar, segmentectomy, and nonanatomic wedge resections, are performed in a variety of hospitals, including those with thoracic surgery residency (TSR), general surgery residency (GSR), no surgery residency (NSR), and no residency (NR).

Pay-for-performance incentive programs for such specialty surgeons have expanded over the last decade and shifted their reimbursement strategies from process measures to outcome effectiveness measures..$^{7-9}$ Establishing assessable and computable metrics among surgical subspecialties is important for effective comparisons. ${ }^{9}$ Furthermore, failure to discriminate the outcomes between thoracic surgery and general surgery teaching hospitals may falsely suggest similar outcomes at these centers.

On the basis of volume-to-outcome associations, ${ }^{10,11}$ currently considered one of the benchmarks for various outcome and quality programs, ${ }^{12}$ the systematic channeling of patients to disease-specific specialists at teaching hospitals has grown. ${ }^{13,14}$ Clinical outcomes ultimately will drive referral patterns, costs, and access to care as interpreted by patients, providers, and payers. On the basis of these characteristics, we hypothesized that pulmonary resections performed at teaching and nonteaching hospitals have different outcomes. Although this question has been partly 


\section{Abbreviations and Acronyms \\ ACGME = Accreditation Council for Graduate Medical Education \\ AHRQ = Agency for Healthcare Research and \\ AUC = area under the receiver operating characteristic curve \\ GSR $=$ general surgery residency \\ ICD-9-CM = International Classification of \\ Diseases, 9th Revision, Clinical \\ Modification \\ NIS $\quad=$ Nationwide Inpatient Sample \\ NR $\quad=$ no residency \\ NSR $=$ no surgery residency \\ TSR $=$ thoracic surgery residency}

studied in the context of lung cancer-related resections, ${ }^{15,16}$ a contemporary series evaluating the impact of all-cause pulmonary resections performed at any type of hospital in the United States remains unknown. In addition, we postulated that even among surgery teaching hospitals, TSR and GSR programs would have differences in outcomes.

\section{MATERIALS AND METHODS}

\section{Data Sources}

Data were abstracted from the 2003 to 2009 Nationwide Inpatient Sample (NIS). The NIS is the largest Healthcare Cost and Utilization Project all-payer inpatient database, sponsored by the Agency for Healthcare Research and Quality (AHRQ). ${ }^{17}$ No data imputations were performed, datasets were reviewed for any systematically missing values, and records accordingly were excluded from evaluation.

Hospital identifiers were abstracted from the American Hospital Association 2009 database. The NIS and American Hospital Association databases contain deidentified administrative-level data and were not considered human subjects research; thus, they were exempted from review by the University of Virginia's Human Investigation Committee.

\section{Patients and Groups}

Patients were selected $(\mathrm{N}=498,099)$ if they underwent a pneumonectomy, lobar, segmentectomy, or a nonanatomic wedge resection using International Classification of Diseases, 9th Revision, Clinical Modification (ICD-9-CM) codes-pneumonectomy: 32.5, 32.50, and 32.59; lobar: 32.4, 32.41, and 32.49; segmentectomy: 32.3, 32.30, and 32.39; and nonanatomic wedge resection: 32.29. All procedure codes (PR1-PR15) were queried to identify patients as having undergone either of these procedures regardless of indication. Cases in which multiple pulmonary resections occurred were assigned to a group on the basis of the first resection code to avoid double counting any record. Patient risk factors were assessed using the AHRQ comorbidities developed by Elixhauser and colleagues, ${ }^{18}$ which provide effective adjustments for mortality risk among surgical populations. ${ }^{19}$

\section{Hospital Educational Status Assignment}

Hospital educational status was determined by identifying all Thoracic Surgery or General Surgery residency training programs accredited by the Accreditation Council for Graduate Medical Education (ACGME), as identified by the American Medical Association Fellowship and Residency Electronic Interactive Database Access Online System. ${ }^{20}$ On the basis of these strata, hospitals were differentiated into TSR $(\mathrm{N}=73)$, GSR $(\mathrm{N}=244)$, NSR $(\mathrm{N}=1135)$, and NR $(\mathrm{N}=4133)$ hospitals. ACGME training programs where a Thoracic Surgery and General Surgery residency coexist were coded as TSR hospitals. The American Hospital Association, American Medical Association Fellowship and Residency Electronic Interactive Database Access Online System, and NIS databases were then cross-linked by an identifier key, while maintaining the integrity of the deidentified data among NIS records for assigning teaching status.

\section{Outcomes of Interest}

In-hospital mortality, risk of complication, and failure to rescue, defined as mortality after a complication, were the primary outcomes of interest. Risk of complication included any complication that was identified and limited to the hospital admission recorded ICD-9-CM codes. Because the NIS contains inpatient data, only complications occurring after hospital discharge cannot be evaluated. Several ICD-9-CM codes were adapted from previously described work to identify the occurrence of a complication. $^{21}$

\section{Statistical Analysis}

Descriptive statistics were computed as described. ${ }^{21}$ Hospital educational status annual mean case volume, unadjusted mortality, complication rate, and failure to rescue were calculated. Hierarchical generalized linear equations calculated the adjusted odds of the dependent variable (by controlling for differences in case-mix, hospitalization, and administrative features, ie, [1] patient characteristics such as risk factors, gender, and age; and [2] hospital and administrative characteristics such as admission month, year, center bed size, and region of the United States where the center is located). Model covariates were selected a priori on the basis of decisions about their likely contribution toward the prediction of the outcome. ${ }^{22-25}$ All covariates selected for inclusion were retained in the final models. The models' predictive capacity to discriminate was measured by computing the area under the receiver operating characteristic curve (AUC).

We present the results from mixed-effects models. There was no discernible difference in model performance characteristics or parameter estimates between these 2 approaches. To confirm model validation, we created randomly resampled equal split-samples from the original annual dataset(s), using the derivation dataset(s) to develop our models, and the confirmatory dataset(s) for validation. These 2 sets of models had minimal decrement (did not change by $>10 \%$ ). All data were analyzed using IBM SPSS Complex Samples 20 (SPSS Inc, An IBM Co, Armonk, NY). Adjustments for the stratification structure in the NIS datasets were made using appropriate discharge weights.

\section{RESULTS}

Annual case volumes are lowest at hospitals with TSR programs. TSR hospitals performed the fewest pulmonary resections annually (16\%) (Tables 1 and 2). NR hospitals $(\mathrm{N}=4133)$ performed the highest proportion of pulmonary resections annually (39\%), and GSR teaching hospitals $(\mathrm{N}=707)$ performed approximately more than half the proportion of pulmonary resections versus NSR teaching hospitals ( $\mathrm{N}=1135)$ (GSR: $17 \%$, NSR: $28 \%$ ). There was a $34 \%$ decrease in association with pulmonary resection volume at TSR hospitals $(\mathrm{N}=331)$ between 2003 and 2009. These data confirm that NR hospitals perform more pulmonary resections than hospitals with surgery residencies. 
TABLE 1. Distribution of pulmonary resections by hospital educational status

\begin{tabular}{lcrrr}
\hline & Pneumonectomy & Lobar & Segmentectomy & Nonanatomic wedge \\
\hline TSR & $4441(19.62 \%)$ & $30,936(13.91 \%)$ & $7608(17.36 \%)$ & $39,060(18.70 \%)$ \\
GSR & $3847(17.00 \%)$ & $37,815(17.00 \%)$ & $8412(19.20 \%)$ & $34,762(16.64 \%)$ \\
NSR & $6676(29.50 \%)$ & $63,658(28.62 \%)$ & $10,803(24.65 \%)$ & $56,758(27.17 \%)$ \\
NR & $7670(33.89 \%)$ & $90,031(40.47 \%)$ & $17,000(38.79 \%)$ & $78,299(37.49 \%)$ \\
\hline
\end{tabular}

$T S R$, Thoracic surgery residency; GSR, general surgery residency; NSR, no surgery residency; NR, no residency.

Unadjusted mortality, the risk of developing a complication, and failure to rescue are lower at TSR hospitals. Among pneumonectomy, segmentectomy, and nonanatomic wedge resection recipients, the lowest unadjusted mortality rates were noted at TSR hospitals (Figure 1, A). In comparison, the highest mortality occurred at NR hospitals. Likewise, the lowest unadjusted complication rate in patients undergoing lobar, segmentectomy, and nonanatomic wedge resection was also associated with TSR hospitals (Figure 1,B). Failure to rescue after lobar and segmentectomy resection was lowest at GSR teaching hospitals, whereas patients undergoing pneumonectomy and nonanatomic wedge resection had the lowest failure to rescue at TSR hospitals (Figure 1,C). Taken together, these data suggest that TSR hospitals have the lowest inhospital mortality after pulmonary resection, with low post-resection complication rates. Furthermore, when a complication does occur, the ability to rescue such patients occurs most efficiently at TSR hospitals.

Adjusted mortality after pulmonary resection is lowest at hospitals with thoracic surgery residencies. After case-mix adjustment (Tables E1-E4), TSR hospitals were associated with an improvement in the adjusted odds ratio (OR) of mortality after pneumonectomy by more than 35\% compared with GSR hospitals (Table 3). Likewise, TSR hospitals were also associated with a reduction in the adjusted OR of mortality after pneumonectomy by $31 \%$ compared with NSR hospitals (AUC, 0.87). However, this reduction in mortality by TSR hospitals was not as robust after lobar resection, whereas GSR hospitals were associated with a $37 \%$ reduction in mortality compared with NR hospitals (AUC, 0.91). Conversely, on the basis of the unstandardized regression coefficient $B$ measured on the same scale, there was a clear mortality benefit to recipients

TABLE 2. Unadjusted mortality, complication rate, failure to rescue, and mean annual case volume for all pulmonary resections by hospital educational status

\begin{tabular}{lcccc}
\hline & $\begin{array}{c}\text { Mean annual } \\
\text { case volume }\end{array}$ & Mortality & $\begin{array}{c}\text { Complication } \\
\text { rate }\end{array}$ & $\begin{array}{c}\text { Failure to } \\
\text { rescue }\end{array}$ \\
\hline TSR & $11,721(16 \%)$ & $13.20 \%$ & $14.10 \%$ & $13.00 \%$ \\
GSR & $12,119(17 \%)$ & $14.60 \%$ & $16.90 \%$ & $14.90 \%$ \\
NSR & $19,699(28 \%)$ & $28.80 \%$ & $28.50 \%$ & $29.90 \%$ \\
NR & $27,571(39 \%)$ & $43.40 \%$ & $40.40 \%$ & $42.20 \%$ \\
\hline
\end{tabular}

$T S R$, Thoracic surgery residency; GSR, general surgery residency; $N S R$, no surgery residency; $N R$, no residency. of segmentectomy and nonanatomic pulmonary resections when they underwent their procedure at a TSR hospital (AUC, 0.89 and 0.91, respectively). TSR hospitals were associated with a reduction in the adjusted odds of mortality after segmentectomy by $35 \%$ and after nonanatomic wedge resection by $24 \%$ in comparison with NR hospitals. Collectively, these data suggest that TSR hospitals are independently associated with a reduction in the adjusted odds of death after pulmonary resections.

Adjusted risk of complication rate after pulmonary resection is lower in hospitals with thoracic surgery residencies. Among pneumonectomy recipients (Tables E1-E4), GSR hospitals were $24 \%$ less likely to be associated with the adjusted odds of developing a complication compared with NR hospitals (Table 4). TSR hospitals had a similar, yet slightly lower reduction of $19 \%$ (AUC, 0.85 ). In patients who underwent a lobar or nonanatomic wedge resection, TSR hospitals had significant reductions in the adjusted OR of the risk of developing any complication (AUC, 0.85). Likewise, in patients undergoing segmentectomy, TSR hospitals were associated with the greatest reduction in the risk of developing a complication by $23 \%$ compared with NR hospitals (AUC, 0.85). Insomuch as GSR hospitals were beneficial for patients undergoing pneumonectomy, TSR hospitals were independently associated with a reduction in the odds of developing a complication after lobar, segmentectomy, and nonanatomic wedge resections.

Adjusted risk of failure to rescue after pulmonary resection is reduced at hospitals with TSR programs. The reduction in the adjusted odds of failing to rescue a patient from death after developing a complication after a pneumonectomy was greatest at TSR hospitals (Table 5). Compared with NR hospitals (Tables E1-E4), TSR hospitals were associated with a reduction in the adjusted odds of failure to rescue in these patients by $66 \%$ (AUC, 0.88). Of note, NR teaching hospitals were associated with an increase in the adjusted OR of failure to rescue after segmentectomy (AUC, 0.93) and nonanatomic wedge resection (AUC, 0.92). Collectively, these data indicate that the ability to detect a complication after surgery and avoid subsequent mortality is greatest at TSR hospitals.

\section{DISCUSSION}

The current study examines the contemporary performance across the most commonly offered pulmonary 

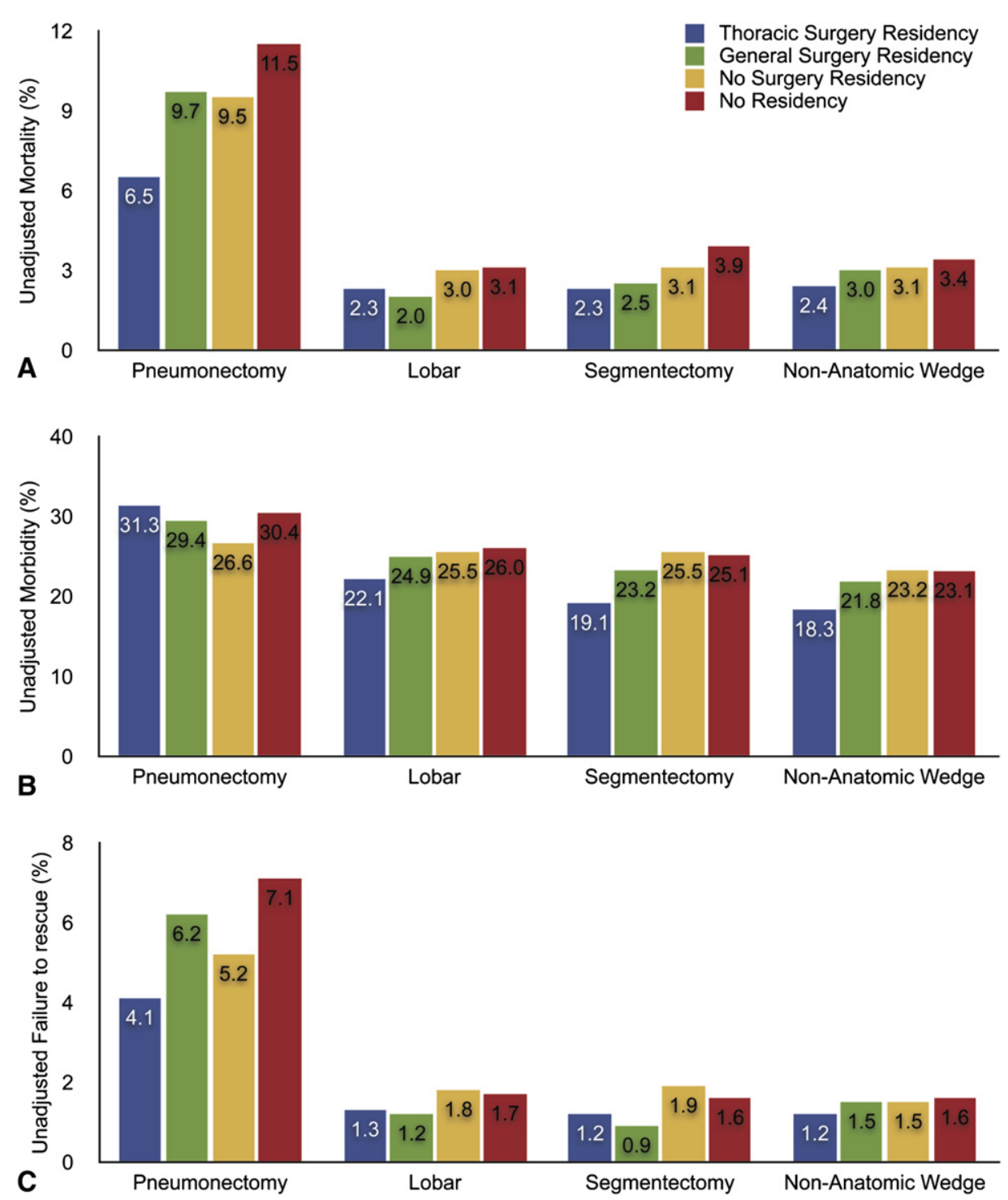

FIGURE 1. Proportion of unadjusted mortality (A), risk of developing any complication (B), and failure to rescue (C) across hospital subtypes after pulmonary resection.

resections in the United States at teaching and nonteaching hospitals using a population-based analysis. On the basis of these analyses, the hospital TSR status should be considered an independent prognostic indicator of quality in pulmonary resections. There are several independent lines of evidence in support of this assertion. First, we found that unadjusted mortality for procedures was lower at TSR hospitals, as was the risk of developing any complication. Second, the adjusted OR of the risk of developing any complication after lobar, segmentectomy, or nonanatomic wedge resection was lower at TSR versus GSR hospitals. Third, among pneumonectomy recipients, TSR hospital status independently reduced the adjusted OR of failure to rescue by more than $25 \%$ compared with NSR. Fourth, again in patients undergoing pneumonectomy, TSR programs lowered the adjusted OR of death by more than $30 \%$ compared with GSR programs. Taken together, these data support the hypothesis that TSR programs offers additional benefit to patients undergoing pulmonary resection.

Cheung and colleagues ${ }^{15}$ evaluated 13,469 patients with lung cancer who underwent resection with curative intent at Association of American Medical Colleges teaching institutions between 1998 and 2002 in the Florida Cancer Data System linked to the Florida Agency for Health Care Administration database and found that teaching status was associated with a lower adjusted OR of mortality compared with nonteaching facilities. Furthermore, the authors also reported that median survival, 90-day, and 5-year mortality were all lower at high-volume and teaching hospitals compared with low-volume and nonteaching hospitals. ${ }^{15}$ 
TABLE 3. Hierarchical regression models comparing hospital residency status as an independent indicator of mortality across pulmonary resections

\begin{tabular}{|c|c|c|c|c|c|c|}
\hline & \multicolumn{3}{|c|}{ Pneumonectomy } & \multicolumn{3}{|c|}{ Lobar } \\
\hline & Adjusted OR (95\% CI) & $R^{2}, \mathrm{AUC}$ & $P$ value & Adjusted OR (95\% CI) & $R^{2}, \mathrm{AUC}$ & $P$ value \\
\hline TSR & $0.33(0.21-0.53)$ & $31 \%, 0.87$ & $<.001$ & $0.83(0.66-1.05)$ & $31 \%, 0.91$ & .001 \\
\hline GSR & $0.69(0.47-0.99)$ & & & $0.63(0.50-0.79)$ & & \\
\hline \multirow[t]{2}{*}{ NSR } & $0.64(0.48-0.85)$ & & & $0.95(0.80-1.13)$ & & \\
\hline & \multicolumn{3}{|c|}{ Segmentectomy } & \multicolumn{3}{|c|}{ Nonanatomic wedge } \\
\hline TSR & $0.65(0.39-1.08)$ & $28 \%, 0.89$ & .38 & $0.76(0.60-0.95)$ & $32 \%, 0.91$ & .12 \\
\hline GSR & $0.86(0.58-1.28)$ & & & $0.92(0.75-1.13)$ & & \\
\hline NSR & $0.99(0.70-1.42)$ & & & $0.98(0.82-1.16)$ & & \\
\hline
\end{tabular}

Reference, NR hospital. OR, Odds ratio; $C I$, confidence interval; $R^{2}$, Nagelkerke $R^{2} ; A U C$, area under receiver operating characteristic curve; $T S R$, thoracic surgery residency; $G S R$, general surgery residency; $N S R$, no surgery residency.

Although the current study does not compare volume-based outcomes, we similarly demonstrate that undergoing a pulmonary resection at a surgery teaching hospital offers a mortality benefit to patients. This benefit is even more enhanced when patients undergo resections at hospitals with TSR programs. In contrast to the work by Cheung and colleagues, ${ }^{15}$ our work is performed in a more contemporary series and provides the most current assessment of outcomes in pulmonary resection recipients in the United States.

A comparison between The Society of Thoracic Surgeons General Thoracic Surgery Database and NIS (2002-2008) by Lapar and colleagues ${ }^{26}$ demonstrated a $3 \%$ unadjusted mortality rate and $23.6 \%$ complication rate after pulmonary resections (ie, sublobar resection, lobectomy, and pneumonectomy) performed for primary lung cancer in the NIS. The current study using the NIS (2003-2009) includes pulmonary resections for all causes and exhibits similar mortality and complication rates. Notwithstanding coding differences between these studies, the consistency in observations validates our results. Ellis and colleagues $^{27}$ examined the NIS (1998-2007) and found that thoracic surgeons had greater lymphadenectomy rates and fewer postoperative complications. These data are supportive of our results and when taken in the context of the current findings also suggest that cases staffed by thoracic surgeons at TSR centers have better outcomes. ${ }^{27}$ In 2009 , Farjah and colleagues ${ }^{28}$ reported that general thoracic surgeons performed preoperative and intraoperative staging more often than general surgeons. Collectively, this study and others ${ }^{26-28}$ identify multiple reasons why outcomes for pulmonary resection procedures are superior at hospitals with TSR programs.

In 2008, Meguid and associates ${ }^{16}$ from Johns Hopkins reported on the association between mortality and ACGMEdefined hospital teaching status in patients with lung cancer using the NIS (1998-2004). This study examined recipients of pneumonectomy, segmentectomy, and lobectomy, and their results demonstrated a $17 \%$ mortality benefit for patients undergoing resection at teaching hospitals. In contrast to the current study, Meguid and colleagues ${ }^{16}$ found no additional mortality benefit to patients receiving a pulmonary resection at hospitals with a TSR program. Despite the fact that the focus and hypotheses of the 2 studies were different, there are several plausible explanations for the variation in our findings. Insomuch as subtle differences exist between the 2 study populations, our work reflects the most current data available at the national level. In addition, we base our findings stratified by the currently approved ACGME programs for thoracic and general surgery. ${ }^{29}$ Our risk adjustments were made using the Elixhauser comorbidities

TABLE 4. Hierarchical regression models comparing hospital residency status as an independent indicator of the risk of any complication across pulmonary resections

\begin{tabular}{|c|c|c|c|c|c|c|}
\hline & \multicolumn{3}{|c|}{ Pneumonectomy } & \multicolumn{3}{|c|}{ Lobar } \\
\hline & Adjusted OR $(95 \%$ CI $)$ & $R^{2}, \mathrm{AUC}$ & $P$ value & Adjusted OR $(95 \%$ CI $)$ & $R^{2}, \mathrm{AUC}$ & $P$ value \\
\hline TSR & $0.81(0.62-1.05)$ & $44 \%, 0.85$ & .05 & $0.85(0.77-0.93)$ & $40 \%, 0.85$ & $<.001$ \\
\hline GSR & $0.76(0.59-0.98)$ & & & $0.97(0.90-1.05)$ & & \\
\hline \multirow[t]{2}{*}{ NSR } & $0.78(0.63-0.96)$ & & & $0.89(0.83-0.95)$ & & \\
\hline & \multicolumn{3}{|c|}{ Segmentectomy } & \multicolumn{3}{|c|}{ Nonanatomic wedge } \\
\hline TSR & $0.77(0.63-0.94)$ & $41 \%, 0.85$ & .06 & $0.72(0.65-0.79)$ & $37 \%, 0.85$ & $<.001$ \\
\hline GSR & $0.94(0.79-1.11)$ & & & $0.98(0.89-1.06)$ & & \\
\hline NSR & $0.89(0.77-1.04)$ & & & $0.92(0.86-1.00)$ & & \\
\hline
\end{tabular}

Reference, NR hospital. $O R$, Odds ratio; $C I$, confidence interval; $R^{2}$, Nagelkerke $R^{2} ; A U C$, area under receiver operating characteristic curve; $T S R$, thoracic surgery residency; $G S R$, general surgery residency; $N S R$, no surgery residency. 
TABLE 5. Hierarchical regression models comparing hospital residency status as an independent indicator of the failure to rescue patients after undergoing a pulmonary resection

\begin{tabular}{|c|c|c|c|c|c|c|}
\hline & \multicolumn{3}{|c|}{ Pneumonectomy } & \multicolumn{3}{|c|}{ Lobar } \\
\hline & Adjusted OR (95\% CI) & $R^{2}, \mathrm{AUC}$ & $P$ value & Adjusted OR (95\% CI) & $R^{2}, \mathrm{AUC}$ & $P$ value \\
\hline TSR & $0.34(0.19-0.61)$ & $32 \%, 0.88$ & .001 & $0.79(0.58-1.08)$ & $32 \%, 0.92$ & .13 \\
\hline GSR & $0.80(0.51-1.27)$ & & & $0.73(0.54-0.97)$ & & \\
\hline \multirow[t]{2}{*}{ NSR } & $0.62(0.42-0.90)$ & & & $0.96(0.77-1.20)$ & & \\
\hline & \multicolumn{3}{|c|}{ Segmentectomy } & \multicolumn{3}{|c|}{ Nonanatomic wedge } \\
\hline TSR & $1.09(0.52-2.30)$ & $36 \%, 0.93$ & .03 & $0.75(0.54-1.05)$ & $31 \%, 0.92$ & .32 \\
\hline GSR & $0.77(0.41-1.44)$ & & & $1.01(0.76-1.35)$ & & \\
\hline NSR & $1.86(1.11-3.11)$ & & & $1.02(0.80-1.31)$ & & \\
\hline
\end{tabular}

Reference, NR hospital. $O R$, Odds ratio; $C I$, confidence interval; $R^{2}$, Nagelkerke $R^{2} ; A U C$, area under receiver operating characteristic curve; TSR, thoracic surgery residency; $G S R$, general surgery residency; $N S R$, no surgery residency.

instead of the Charlson Index and examination of the risk of any complication and failure to rescue, which all provide unique facets to the current study. An additional unique observation of our study was the particularly disturbing finding that failure to rescue is so poor in hospitals without residencies, suggesting that there is a failure to recognize significant postoperative complications and then respond appropriately.

\section{Study Limitations}

There are limitations to our study. The focus of this study was to perform a contemporary examination among teaching and nonteaching hospital outcomes after commonly performed pulmonary resections, and not to assess surgeon or hospital volume impact on outcomes. In addition, it is not possible with the NIS database to ascertain the certification status of the surgeon as to whether he or she has board certification by the American Board of Thoracic Surgery. The NIS is a large database with the potential for erroneous coding among ICD-9-CM procedure codes. For example, in patients who had multiple pulmonary resections assigned, groups were coded on the basis of the first pulmonary resection code and may not necessarily reflect the most important or significant procedure performed during the admission. However, the NIS represents a random sampling of discharge-level data that are externally and internally validated. Therefore, coding errors should be homogenously distributed across groups, equally affecting the study populations in this evaluation. There are also limitations using the Elixhauser AHRQ comorbidities to assess patient risk factors. Several important risk factors known to influence pulmonary resection surgery outcomes, such as patient age, performance status, and preoperative diagnosis, are not in these categorizations.

\section{CONCLUSIONS}

In comparison with other hospitals, specifically GSR teaching hospitals, and despite a steady decline in annual pulmonary resection volume, TSR teaching hospitals have lower mortality after pneumonectomy, segmentectomy, and nonanatomic wedge resections. In addition, in comparison with NR hospitals, morbidity after lobar, segmentectomy, and nonanatomic wedge resection is lower at TSR versus GSR teaching hospitals. The risk of failure to rescue after pneumonectomy and nonanatomic wedge resection is least associated with TSR teaching hospitals. The mechanisms that confer these benefits to patients undergoing pulmonary resections at TSR teaching hospitals require further exploration. Nevertheless, these data support using TSR hospital teaching status as an independent prognostic indicator of outcomes in pulmonary resections.

\section{References}

1. Kahn J. HealthGrades: playing doctor on the Web. Fortune. 1999;140:318.

2. Osborne NH, Nicholas LH, Ghaferi AA, Upchurch GR Jr, Dimick JB. Do popular media and internet-based hospital quality ratings identify hospitals with better cardiovascular surgery outcomes? J Am Coll Surg. 2010;210:87-92.

3. Robinowitz DL, Dudley RA. Public reporting of provider performance: can its impact be made greater? Ann Rev Public Health. 2006;27:517-36.

4. Auerbach AD, Hilton JF, Maselli J, Pekow PS, Rothberg MB, Lindenauer PK Shop for quality or volume? Volume, quality, and outcomes of coronary artery bypass surgery. Ann Intern Med. 2009;150:696-704.

5. Lindenauer P. Public reporting and pay-for-performance programs in perioperative medicine: are they meeting their goals? Cleve Clin J Med. 2009;76(Suppl 4): S3-8.

6. Rothberg MB, Benjamin EM, Lindenauer PK. Public reporting of hospital quality: recommendations to benefit patients and hospitals. J Hosp Med. 2009;4:541-5.

7. Wharam JF, Frank MB, Rosland AM, Paasche-Orlow MK, Farber NJ, Sinsky C, et al. "Pay-for-performance" as a quality improvement tool: perceptions and policy recommendations of physicians and program leaders. Qual Manag Health Care. 2011;20:234-45

8. Taylor MD, Nagji AS, Bhamidipati CM, Theodosakis N, Kozower BD, Lau CL, et al. Tumor recurrence after complete resection for non-small cell lung cancer. Ann Thorac Surg. 2012;93:1813-21.

9. Greenberg JO, Dudley JC, Ferris TG. Engaging specialists in performanceincentive programs. N Engl J Med. 2010;362:1558-60.

10. Birkmeyer JD, Dimick JB, Staiger DO. Operative mortality and procedure volume as predictors of subsequent hospital performance. Ann Surg. 2006;243:411-7.

11. Birkmeyer JD, Stukel TA, Siewers AE, Goodney PP, Wennberg DE, Lucas FL. Surgeon volume and operative mortality in the United States. $N$ Engl J Med. 2003;349:2117-27.

12. Hollingsworth JM, Krein SL, Miller DC, DeMonner S, Hollenbeck BK. Payer leverage and hospital compliance with a benchmark: a population-based observational study. BMC Health Serv Res. 2007;7:112. 
13. White DB, Bonham VL, Jenkins J, Stevens N, McBride CM. Too many referrals of low-risk women for BRCA1/2 genetic services by family physicians. Cancer Epidemiol Biomarkers Prev. 2008;17:2980-6.

14. Carter JE, Neff LP, Holmes JH 4th. Adherence to burn center referral criteria: are patients appropriately being referred? J Burn Care Res. 2010;31:26-30.

15. Cheung MC, Hamilton K, Sherman R, Byrne MM, Nguyen DM, Franceschi D, et al. Impact of teaching facility status and high-volume centers on outcomes for lung cancer resection: an examination of 13,469 surgical patients. Ann Surg Oncol. 2009;16:3-13.

16. Meguid RA, Brooke BS, Chang DC, Sherwood JT, Brock MV, Yang SC. Are surgical outcomes for lung cancer resections improved at teaching hospitals? Ann Thorac Surg. 2008;85:1015-25.

17. Nationwide Inpatient Sample. Healthcare Cost Utilization Project. Rockville, MD: Agency for Healthcare Research and Quality; 2005-2009.

18. Elixhauser A, Steiner C, Harris DR, Coffey RM. Comorbidity measures for use with administrative data. Med Care. 1998;36:8-27.

19. Southern DA, Quan H, Ghali WA. Comparison of the Elixhauser and Charlson/ Deyo methods of comorbidity measurement in administrative data. Med Care. 2004;42:355-60.

20. FREIDA Online. Available at: http://www.ama-assn.org/ama/pub/educationcareers/graduate-medical-education/freida-online.page. Accessed May 15, 2011.

21. Bhamidipati CM, LaPar DJ, Mehta GS, Kern JA, Kron IL, Upchurch GR Jr, et al. Have thoracic endografting outcomes improved since US Food and Drug Administration approval? Ann Thorac Surg. 2011;91:1314-22.

22. Gopaldas RR, Bakaeen FG, Dao TK, Coselli JS, LeMaire SA, Huh J, et al. Outcomes of concomitant aortic valve replacement and coronary artery bypass grafting at teaching hospitals versus nonteaching hospitals. J Thorac Cardiovasc Surg. 2012;143:648-55.

23. Lapar DJ, Mery CM, Kozower BD, Kern JA, Kron IL, Stukenborg GJ, et al. The effect of surgeon volume on mortality for off-pump coronary artery bypass grafting. J Thorac Cardiovasc Surg. 2012;143:854-63.

24. Meguid RA, Weiss ES, Chang DC, Brock MV, Yang SC. The effect of volume on esophageal cancer resections: what constitutes acceptable resection volumes for centers of excellence? J Thorac Cardiovasc Surg. 2009;137:23-9.

25. Vassileva CM, Shabosky J, Boley T, Markwell S, Hazelrigg S. Tricuspid valve surgery: the past 10 years from the Nationwide Inpatient Sample (NIS) database. J Thorac Cardiovasc Surg. 2012;143:1043-9.

26. Lapar DJ, Bhamidipati CM, Lau CL, Jones DR, Kozower BD. The Society of Thoracic Surgeons General Thoracic Surgery Database: establishing generalizability to national lung cancer resection outcomes. Ann Thorac Surg. 2012;94: 216-21.

27. Ellis MC, Diggs BS, Vetto JT, Schipper PH. Intraoperative oncologic staging and outcomes for lung cancer resection vary by surgeon specialty. Ann Thorac Surg. 2011;92:1958-64.

28. Farjah F, Flum DR, Varghese TK Jr, Symons RG, Wood DE. Surgeon specialty and long-term survival after pulmonary resection for lung cancer. Ann Thorac Surg. 2009;87:995-1006

29. Accreditation Council for Graduate Medical Education. Available at: http:// www.acgme.org. Accessed May 15, 2011.

\section{Discussion}

Dr Mark J. Krasna (Neptune, NJ). Studying quality outcomes for surgical procedures is important as a tool for self-improvement and process improvement, and because these data should be available to the consumer, the patient, for reference when a patient is researching the options for care. The idea of developing a referral system for patients who need complex procedures to go to hospitals with the best outcomes is enticing, because it would provide for the best possible care for our patients. At the same time, we must weigh this against the inconvenience to patients and their wishes when they want to remain as close to home as possible.

This study purported to demonstrate the superiority of outcomes after pulmonary resection based on teaching status of the hospital where the procedure took place. The data suggest that the mortality and morbidity were lowest for thoracic teaching hospitals, to which we can hypothesize many explanations.
Although the quality of the procedure was superior among thoracic teaching hospitals, they accounted for only $16 \%$ of the 500,000 patients treated. In fact, approximately $40 \%$ were done at purely community hospitals without any teaching program.

If we were to take the leap forward and recommend or by government edict decree that all patients should undergo these procedures at thoracic teaching hospitals, it would require us to significantly alter the overall resource allocation for thoracic surgery and cancer care in this country. Not only would the existing thoracic teaching services not be able to completely care for all of our patients needing pulmonary resection, but even if patients were forced to receive care at a regional thoracic teaching hospital, we do not have enough qualified thoracic surgeons in our specialty to care for all those patients at those hospitals. In fact, the current trend in employment and training for thoracic residents suggests that there will not be enough thoracic surgeons in 10 to 20 years given the current number of trainees and the current training programs. Some new version of the health care reform act obviously will be required to achieve this lofty goal and make it feasible.

Finally, it is important as we try to clarify quality care to identify common factors that lead to success, such as was undertaken by the Leapfrog group when they looked at coronary artery bypass procedures and major thoracic resections. If specific behaviors or practices can be identified, these could be taught to the remaining community of thoracic surgeons whether they are in teaching or nonteaching hospitals.

The ultimate goal in quality improvement is to improve the quality of care overall throughout the health care system across the United States and the globe. The only way to do that is to help move the indicator on the dashboard stepwise as we try to improve care at each individual hospital. This will allow us to make important improvements while we await broad policy change to allocate patients to regional centers of excellence.

I have 3 brief questions. Can you give us a breakdown of the surgeons at thoracic teaching hospitals by case volume? In other words, among the excellent programs, were there some surgeons with better outcomes than others? Previous data, for instance, from the coronary artery bypass grafting and vascular surgery literature would say that a particular surgeon or trainee or cases done by residents or cases done by surgeons had an impact.

Likewise, can you give us data from those nonteaching hospitals on whether there was a program in a nonthoracic teaching hospital or a nonteaching hospital with so high a volume that there was a cross point where the quality was met by those hospitals?

Finally, getting to my comments earlier, has your group identified a specific process improvement or series of steps or pathways that we could recommend to the community of thoracic surgeons that would result in improved outcomes if adopted?

Dr Bhamidipati. Some of your questions are difficult to answer in the context of the current dataset that we have examined, specifically because we used the NIS, and I think you are privy to some of those issues as far as unique identifiers changing from year to year and not being able to track physician sampling from one year to the next as the data are collected.

We did not analyze, as you know, surgeon or hospital volume in this particular analysis, but certainly volume has been an issue; both hospital and surgeon volumes have been factors in several 
recent examinations of this type of volume outcome-associated work. For example, last year at the American Association for Thoracic Surgery, our group presented that hospital volume was less important and that surgeon volume was more important in offpump coronary bypass graft operations. Also, at the most recently held American Surgical Association meeting a couple of days ago, we presented that again (hospital volume is not as important), and in that particular study we didn't really look at surgeon volume.

If you look at volume outcome studies, few have actually looked at volume as a continuous variable. A lot of the studies that examine volume outcomes, be that surgeon or hospital volume, have actually created quintiles or terciles where they have used arbitrary cutoff points to allocate volume groups as an indicator for the dependent variable.

The problem with that kind of analysis, as you know, is that the interval is considered flat, that is, the hospital or surgeon who did 10 cases would have the same outcome as the hospital or surgeon who did only 1 case. The best way to do those analyses is to then examine this question hierarchically in a linear regression with restricted cubic splines or polynomial piecewise calculations to get a proper sense of how many cases would affect mortality.

Now, 2 other areas to get to what you are saying as far as what are some other potential "mechanistic associations," to use those terms sort of loosely, because "mechanism" implies a causal relationship, are case mix and board certification, which are 2 areas that have also been examined. At the Southern Thoracic Surgical Association in 2008 , there was an article presented by the Oregon group, who actually looked at case mix by threshold and determined what the outcomes were. They found that noncardiac general thoracic surgeons who performed pulmonary resections for lung cancer had the best outcomes and mortality.
To that end, Dr Birkmeyer and colleagues have published several articles in the Annals of Surgery and The New England Journal of Medicine, again looking at the surgical volume/hospital volume issue. Most recently in an article in the The New England Journal of Medicine in 2011, if you look at the pulmonary resection piece, forgetting about the rest of the operations, only $16 \%$ of the variance in the mortality is really explained by hospital volume.

I think in reference to our particular analysis, it seems in the earlier work that has been done, case mix, board certification, and surgeon volume are $3 \mathrm{key}$ areas that are probably reflecting the results we see at teaching hospitals. Your point is well made that we can't just transfer all the workload that is being performed by community hospitals over to academic teaching centers and expect that the absorption after that adoption is going to actually work.

This is an initial study. There is a lot more to come. We have generated more hypotheses, perhaps, than answers for ourselves, and I think it is a step in the right direction to actually get to the answers for better-quality metrics for patients.

Dr Krasna. Do you have any process improvement that you could propose to the group, one we could take home for now, or any hypotheses for your next investigation?

Dr Bhamidipati. I think the next step in this particular work will be to look at surgeon volume and the number of pulmonary resections that are performed and determine how that is associated with mortality, complication rate, and failure to rescue. What is most interesting in the current work is that if you were to actually look at the parameter estimates, that is, the covariates that were responsible to explain the outcome, if we focus on just complications as an outcome, teaching hospital status was one of the highest contributing parameters toward in the regression analysis. So there is definitely something to our work. 
TABLE E1. Model parameter estimates among pneumonectomy recipients $(\mathrm{N}=\mathbf{2 2 , 6 6 3 )}$

\begin{tabular}{|c|c|c|c|c|c|c|}
\hline \multirow[b]{2}{*}{ Covariate } & \multicolumn{2}{|c|}{ Mortality } & \multicolumn{2}{|c|}{ Complication rate } & \multicolumn{2}{|c|}{ Failure to rescue } \\
\hline & Wald chi-square & $P$ value & Wald chi-square & $P$ value & Wald chi-square & $P$ value \\
\hline Month of admission & 7.87 & .73 & 8.99 & .62 & 17.45 & .10 \\
\hline Weekend day admission & 21.76 & $<.001$ & 0.00 & .98 & 0.59 & .44 \\
\hline Year of admission & 14.20 & .03 & 3203.01 & $<.001$ & 122.88 & $<.001$ \\
\hline Hospital teaching status & 26.11 & $<.001$ & 49.36 & $<.001$ & 3.53 & .32 \\
\hline Elective/nonelective & 7.89 & .01 & 15.45 & $<.001$ & 59.94 & $<.001$ \\
\hline Female gender & 0.60 & .44 & 6.00 & .01 & 0.06 & .81 \\
\hline Hospital bed size & 4.75 & .09 & 3.24 & .20 & 0.39 & .82 \\
\hline Rural/urban location & 0.90 & .34 & 0.41 & .52 & 1.70 & .19 \\
\hline US region & 12.48 & .01 & 18.22 & $<.001$ & 12.66 & .01 \\
\hline Insurance payer status & 1142.15 & $<.001$ & 5.43 & .37 & 1739.48 & $<.001$ \\
\hline Age & 1.91 & .17 & 6.53 & .01 & 57.57 & $<.001$ \\
\hline
\end{tabular}

All models adjusted for Elixhauser comorbidities (patient risk factors).

TABLE E2. Model parameter estimates among lobar resection recipients $(\mathbf{N}=\mathbf{2 2 2 , 5 8 6 )}$

\begin{tabular}{|c|c|c|c|c|c|c|}
\hline \multirow[b]{2}{*}{ Covariate } & \multicolumn{2}{|c|}{ Mortality } & \multicolumn{2}{|c|}{ Complication rate } & \multicolumn{2}{|c|}{ Failure to rescue } \\
\hline & Wald chi-square & $P$ value & Wald chi-square & $P$ value & Wald chi-square & $P$ value \\
\hline Month of admission & 12.53 & .33 & 13.67 & .09 & 4.78 & .78 \\
\hline Weekend day admission & 8.44 & .00 & 3.11 & .08 & 0.01 & .93 \\
\hline Year of admission & 76.39 & $<.001$ & 4875.41 & $<.001$ & 192.83 & $<.001$ \\
\hline Hospital teaching status & 16.68 & .00 & 21.04 & $<.001$ & 5.57 & .13 \\
\hline Elective/nonelective & 27.54 & $<.001$ & 17.00 & $<.001$ & 15.87 & $<.001$ \\
\hline Female gender & 10.72 & .00 & 9.61 & .00 & 2.83 & .09 \\
\hline Hospital bed size & 9.20 & .01 & 8.41 & .02 & 3.33 & .19 \\
\hline Rural/urban location & 2.09 & .15 & 1.08 & .30 & 0.63 & .43 \\
\hline US region & 18.17 & $<.001$ & 23.37 & $<.001$ & 7.07 & .07 \\
\hline Insurance payer status & 3915.05 & $<.001$ & 4.32 & .50 & 2437.11 & $<.001$ \\
\hline Age & 35.81 & $<.001$ & 10.87 & .00 & 31.81 & $<.001$ \\
\hline
\end{tabular}

All models adjusted for Elixhauser comorbidities (patient risk factors).

TABLE E3. Model parameter estimates among segmentectomy recipients $(\mathrm{N}=4 \mathbf{4 3 , 8 5 1})$

\begin{tabular}{|c|c|c|c|c|c|c|}
\hline \multirow[b]{2}{*}{ Covariate } & \multicolumn{2}{|c|}{ Mortality } & \multicolumn{2}{|c|}{ Complication rate } & \multicolumn{2}{|c|}{ Failure to rescue } \\
\hline & Wald chi-square & $P$ value & Wald chi-square & $P$ value & Wald chi-square & $P$ value \\
\hline Month of admission & 3.61 & .98 & 9.45 & .58 & 5.28 & .92 \\
\hline Weekend day admission & 1.50 & .22 & 2.22 & .14 & 0.24 & .63 \\
\hline Year of admission & 15.13 & .02 & 926.82 & $<.001$ & 35.77 & $<.001$ \\
\hline Hospital teaching status & 3.06 & .38 & 7.39 & .06 & 8.87 & .03 \\
\hline Elective/nonelective & 14.37 & $<.001$ & 0.19 & .66 & 7.02 & .01 \\
\hline Female gender & 11.72 & .00 & 3.05 & .08 & 5.60 & .02 \\
\hline Hospital bed size & 7.36 & .03 & 12.10 & .00 & 5.76 & .06 \\
\hline Rural/urban location & 4.23 & .04 & 0.01 & .91 & 2716.41 & $<.001$ \\
\hline US region & 1.17 & .76 & 0.22 & .97 & 1.54 & .67 \\
\hline Insurance payer status & 770.11 & $<.001$ & 11.68 & .04 & 341.26 & $<.001$ \\
\hline Age & 2.94 & .09 & 0.08 & .77 & 6.94 & $<.001$ \\
\hline
\end{tabular}

All models adjusted for Elixhauser comorbidities (patient risk factors). 
TABLE E4. Model parameter estimates among nonanatomic wedge resection recipients $(N=208,999)$

\begin{tabular}{|c|c|c|c|c|c|c|}
\hline \multirow[b]{2}{*}{ Covariate } & \multicolumn{2}{|c|}{ Mortality } & \multicolumn{2}{|c|}{ Complication rate } & \multicolumn{2}{|c|}{ Failure to rescue } \\
\hline & Wald chi-square & $P$ value & Wald chi-square & $P$ value & Wald chi-square & $P$ value \\
\hline Month of admission & 16.02 & .14 & 8.99 & .62 & 17.45 & .10 \\
\hline Weekend day admission & 2.69 & .10 & 0.00 & .98 & 0.59 & .44 \\
\hline Year of admission & 33.61 & $<.001$ & 3203.01 & $<.001$ & 122.88 & $<.001$ \\
\hline Hospital teaching status & 5.82 & .12 & 49.36 & $<.001$ & 3.53 & .32 \\
\hline Elective/nonelective & 181.25 & $<.001$ & 15.45 & $<.001$ & 59.94 & .00 \\
\hline Female gender & 4.85 & .03 & 6.00 & .01 & 0.06 & .81 \\
\hline Hospital bed size & 0.01 & .99 & 3.24 & .20 & 0.39 & .82 \\
\hline Rural/urban location & 7.83 & .01 & 0.41 & .52 & 1.70 & .19 \\
\hline US region & 12.13 & .01 & 18.22 & $<.001$ & 12.66 & .01 \\
\hline Insurance payer status & 5050.87 & $<.001$ & 5.43 & .37 & 1739.48 & $<.001$ \\
\hline Age & 83.66 & $<.001$ & 6.53 & .01 & 57.57 & $<.001$ \\
\hline
\end{tabular}

All models adjusted for Elixhauser comorbidities (patient risk factors). 